\title{
EFEKTIFITAS LARVASIDA NABATI DALAM MEMBUNUH LARVA Aedes spp.
}

\author{
Harun Alrasyid Adenan, Muhammad Irfai'i, Isnawati \\ Poltekkes Kemenkes Banjarmasin Jurusan Kesehatan Lingkungan \\ Jl. H. Mistar Cokrokusumo No.1A Banjarbaru Kalimantan Selatan 70714 \\ E-mail: adenanmtw@gmail.com
}

\begin{abstract}
Effectiveness of Vegetable Larvacide in Killing Aedes Spp. Larvae. DHF (Dengue Haemorrhagic Fever) is caused by Aedes spp. vector. Controlling of this disease has used chemist or insecticide. The insecticide for killed larva Aedes spp. is abate. Using insecticide for a while can make vector has resistance. Base on the fact, we need subtances alternative of controlling which can degredable it's from naturall like garlic (Allium sativum), papaya (Carica papaya) core and piper betle. This research aimed for efectivities of larvacide garlic, papaya core and betel vine. This research is a true experimental, used toxicity experiment standart. Result both $L C_{99}$ and Toxid Unit (TU) of larvacide garlic is $7,7 \mathrm{gr} / \mathrm{L}$ and 26,88. Larvacide papaya core is 10,22 $\mathrm{gr} / \mathrm{L}$ and 16,33. Larvacide vine betel is 74,4 $\mathrm{gr} / \mathrm{L}$ and 2,65. Decided of larvacides which efectivest are compared TU value that higher. Based on TU values, larvacide which efectivest and can aplicate for killing larva is garlic. Larvacide of garlic can use in places that contain water which difficult to drained or washed.
\end{abstract}

Keywords: DHF; Aedes spp. Larva; Natural Larvacide; Allium sativum; Carica papaya; piper betle.

\begin{abstract}
Abstrak: Efektifitas Larvasida Nabati dalam Membunuh Larva Aedes Spp. Penyakit DBD di sebabkan oleh vektor Aedes spp. Pengendalian yang paling sering dilakukan saat ini adalah pengendalian secara kimiawi atau insektisida. Insektisida dalam membunuh larva Aedes spp adalah abate. Penggunaan insektisida dalam jangka tertentu akan menimbulkan resistensi vector. Perlu pengendalian alternatif dari bahan yang mudah di degradasi. Salah satunya berasal dari alam, yaitu bawang putih, biji pepaya dan daun sirih. Penelitian ini bertujuan untuk mengetahui efektifitas masing-masing larvasida nabati dari jenis bawang putih (Allium sativum), biji pepaya (Carica papaya) dan daun sirih (piper betle).Jenis penelitian ini bersifat ekseperimental murni dengan menggunakan uji toksisitas standar. Hasil $L C_{99}$ dan nilai toxid unit (TU) dari masing-masing jenis larvasida bawang putih 7,7 gr/L dan 26,88. Larvasida biji pepaya 10,22 gr/L dan 16,33. Larvasida daun sirih adalah 74,4 gr/L dan 2,65. Menentukan jenis larvasida yang efektif dengan cara membandingkan nilai TU yang paling besar. Berdasarkan nilai TU, larvasida yang paling efektif dan yang tepat digunakan dalam membunuh larva Aedes spp. adalah bawang putih. Penggunaan dari larvasida bawang putih dilakukan di tempat-tempat yang sulit dibersihkan.
\end{abstract}

Kata kunci: DBF; larva Aedes spp.; larvasida nabati; Allium sativum; Carica papaya; piper betle.

\section{PENDAHULUAN}

Penyakit demam berdarah dengue (DBD) merupakan salah satu masalah kesehatan lingkungan yang cenderung meningkat jumlah penderita dan semakin luas daerah penyebarannya, sejalan dengan meningkatnya mobilitas dan kepadatan penduduk[1]. Sampai saat ini obat dan vaksin yang benar-benar ampuh untuk menyelamatkan penderita demam berdarah dengue dari bahaya kematian belum berhasil di temukan. Pengendalian penyakit ini masih di titik beratkan kepada usaha pemberantasan nyamuk sebagai vektor dalam penyebarannya. Pemberantasan nyamuk dewasa dapat dilakukan dengan penyemprotan (fogging) menggunakan insektisida yang dalam waktu singkat dapat membatasi penularan. Tetapi cara ini perlu diikuti dengan pemberantasan jentiknya (larva) agar populasi nyamuk penular dapat ditekan serendah-rendahnya[2]. 
Pengendalian yang paling sering dilakukan saat ini adalah pengendalian secara kimiawi, karena dianggap bekerja lebih efektif dan hasilnya cepat terlihat dibandingkan pengendalian secara biologis. Pengendalian yang dilakukan adalah dengan membunuh larva dari vektor untuk memutus rantai penularannya dengan menggunakan abate (temephos). Abate (temephos) merupakan salah satu golongan dari pestisida yang digunakan untuk membunuh serangga pada stadium larva. Abate (temephos) yang digunakan biasanya berbentuk butiran pasir (sand granules) yang kemudian ditaburkan di tempat penampungan air dengan dosis 1 ppm atau 1 gram untuk 10 liter airLaporan resistensi larva Aedes aegypti terhadap abate (temephos) sudah ditemukan di beberapa negara seperti Brazil, Bolivia, Argentina, Kuba, Karibia, dan Thailand. Selain itu juga telah dilaporkan resistensi larva Aedes aegypti terhadap abate (temephos) di Surabaya[3].Salah satu alternatif yang perlu dicoba untuk mengendalikan vector melalui pemberantasan jentik nyamuk Aedes spp. adalah dengan menggunakan larvasida nabati[1].

Penelitian Dwi Sulistyoningsih pada tahun 2016 menunjukkan bahwa bawang putih dalam bentuk larutan dengan dosis 5\% sudah dapat membunuh larva $84 \%$ rata-rata kematian larva Aedes[4]. Penelitian Margo Utomo biji pepaya dalam bentuk serbuk, ditemukan pada dosis 80 $\mathrm{mg} / 100 \mathrm{ml}$ dengan rata-rata kematian larva Aedes sebanyak 50\%[5]. Penelitian Moh. Fahmi tahun 2006, daun sirih dalam bentuk ekstrak sudah dapat membunuh rata-rata kematian larva $88 \%$ dengan dosis $100 \mathrm{mg} / \mathrm{L}[6]$. Perbedaan dengan penelitian ini adalah larvasida nabati bawang putih, biji pepaya dan daun sirih hanya di ditumbuk halus dan lansung di jadikan larvasida agar mudah dalam penerapan di masyarakat.

\section{BAHAN DAN CARA PENELITIAN}

Jenis penelitian yang digunakan adalah true eksperimen (eksperimen murni) adalah eskperimen yang sebenar- nya, karena dalam jenis penelitian ini peneliti dapat mengontrol jalannya eksperimen. Kelompok control dan sampel dipilih secara random (acak). Dalam penelitian ini, bahan alam yaitu bawang putih, biji pepaya dan daun sirih dijadikan larvasida dengan sampel larva Aedes spp. dengan adanya kontrol dan berbagai variasi dosis.Desain penelitian ini adalah dengan pendekatan eksperimental murni yaitu eksperimen sederhana (post-test only control group design) yaitu adanya intervensi atau perlakuan dari peneliti. Dengan adanya control dan perlakuan berupa pemberian larvasida nabati. Penelitian ini dilakukan untuk mengetahui efektifitas larvasida nabati dalam membunuh larva nyamuk Aedes spp.

Sebelum melakukan uji efektifitas ketiga larvasida nabati, dilakukan uji toksisitas pendahuluan terlebih dahulu untuk mendapatkan variasi dosis dalam melanjutkan uji tokisisitas. Dosis untuk uji pendahuluan pada masing-masing jenis larvasida adalah $0 \mathrm{gr} / \mathrm{L}, 1 \mathrm{gr} / \mathrm{L}, 2 \mathrm{gr} / \mathrm{L}, 3$ $\mathrm{gr} / \mathrm{L} 4 \mathrm{gr} / \mathrm{L}$ dan $5 \mathrm{gr} / \mathrm{L}$ sampai mendapatkan dosis maksimum. Setelah itu dilakukan uji toksisitas dengan tujuan untuk mendapatkan dosis yang maksimum dan $\mathrm{LC}_{50}$ (lethal concentration). Data yang diperoleh dari hasil penelitian ini di analisis dengan cara statistic dengan kurva estimasi. Untuk mengetahui perbedaan ketiga jenis larvasida nabati antara bawang putih, biji pepaya dan daun sirih dengan cara membandingkan nilai Toxid Unit (TU).

Larva yang digunakan dalam penelitian ini adalah larva instar III dan IV. Karena Ciri-ciri larva instar III dan IV yaitu telah lengkap struktur anatominya dan jelas tubuhnya dapat dibagi menjadi bagian kepala (chepal), dada (thorax), dan perut (abdomen). Selain itu, secara visual larva instar III dan IV mudah dilihat karena ukuran yang lebih besar[7]. Larva dimasukan masing-masing 10 larva ke dalam box container yan berisi variasi dosis jenis larvasida. Setelah itu hitung kematian larva setelah 2x24 jam. 


\section{HASIL PENELITIAN DAN PEMBAHASAN}

Uji toksisitas Larvasida Bawang Putih (Allium sativum), Larvasida Biji
Pepaya (Carica papaya), dan Larvasida Daun Sirih (piper betle) dapat dilihat pada tabel-tabel berikut ini:

Tabel 1. Uji toksisitas larvasida bawang putih setelah2x24 jam

\begin{tabular}{|c|c|c|c|c|c|c|c|c|}
\hline \multirow{2}{*}{$\begin{array}{l}\text { Dosis } \\
\text { (gr/L) }\end{array}$} & \multirow{2}{*}{$\begin{array}{l}\text { Jumlah larva } \\
\text { (ekor) }\end{array}$} & \multicolumn{3}{|c|}{$\begin{array}{c}\text { Kematian pada } \\
\text { pengulangan (ekor) }\end{array}$} & \multirow[t]{2}{*}{ Rata-rata } & \multirow{2}{*}{$\begin{array}{c}\text { Rata-rata } \\
\quad(\%)\end{array}$} & \multirow[t]{2}{*}{$\mathrm{pH}$} & \multirow{2}{*}{$\begin{array}{c}\text { Suhu } \\
\left({ }^{\circ} \mathrm{C}\right)\end{array}$} \\
\hline & & $\mathrm{Ke}-1$ & Ke-2 & $\mathrm{Ke}-3$ & & & & \\
\hline 0 & 10 & 0 & 0 & 0 & 0 & 0 & 6 & 26 \\
\hline 1 & 10 & 0 & 0 & 0 & 0 & 0 & 6 & 26 \\
\hline 4 & 10 & 8 & 7 & 8 & 7,6 & $76 \%$ & 6 & 26 \\
\hline 7 & 10 & 10 & 10 & 10 & 10 & $100 \%$ & 6 & 26 \\
\hline 10 & 10 & 10 & 10 & 10 & 10 & $100 \%$ & 6 & 26 \\
\hline 13 & 10 & 10 & 10 & 10 & 10 & $100 \%$ & 6 & 26 \\
\hline
\end{tabular}

Tabel 2. $\mathrm{LC}_{50}$ larvasida bawang putih

\begin{tabular}{cccc}
\hline percent & Dosis & Lower & Upper \\
\hline 50 & 3,72812 & 3,12486 & 4,33356 \\
99 & 7,71062 & 6,70558 & 9,36518 \\
\hline
\end{tabular}

Tabel 3. Uji toksisitas larvasida biji pepaya setelah 2x24 jam

\begin{tabular}{|c|c|c|c|c|c|c|c|c|}
\hline \multirow{2}{*}{$\begin{array}{l}\text { Dosis } \\
\text { (gr/L) }\end{array}$} & \multirow{2}{*}{$\begin{array}{l}\text { Jumlah larva } \\
\text { (ekor) }\end{array}$} & \multicolumn{3}{|c|}{$\begin{array}{c}\text { Kematian pada } \\
\text { pengulangan (ekor) }\end{array}$} & \multirow[t]{2}{*}{ Rata-rata } & \multirow{2}{*}{$\begin{array}{c}\text { Rata-rata } \\
(\%)\end{array}$} & \multirow[t]{2}{*}{$\mathrm{pH}$} & \multirow{2}{*}{$\begin{array}{l}\text { Suhu } \\
\left({ }^{0} \mathrm{C}\right)\end{array}$} \\
\hline & & $\mathrm{Ke}-1$ & $\mathrm{Ke}-2$ & $\mathrm{Ke}-3$ & & & & \\
\hline 0 & 10 & 0 & 0 & 0 & 0 & 0 & 6 & 26 \\
\hline 5 & 10 & 4 & 3 & 2 & 3 & $30 \%$ & 6 & 26 \\
\hline 10 & 10 & 10 & 10 & 8 & 9,33 & $93,3 \%$ & 6 & 26 \\
\hline 15 & 10 & 10 & 10 & 10 & 10 & $100 \%$ & 6 & 26 \\
\hline 20 & 10 & 10 & 10 & 10 & 10 & $100 \%$ & 6 & 26 \\
\hline 25 & 10 & 10 & 10 & 10 & 10 & $100 \%$ & 6 & 26 \\
\hline
\end{tabular}

Tabel 4. $\mathrm{LC}_{50}$ larvasida biji pepaya

\begin{tabular}{cccc}
\hline Percent & Dosis & Lower & Upper \\
\hline 50 & 6,12649 & 5,22034 & 7,07788 \\
99 & 10,9579 & 9,39886 & 14,2201 \\
\hline
\end{tabular}

Tabel 5. Uji toksisitas larvasida daun sirih setelah 2x24 jam

\begin{tabular}{|c|c|c|c|c|c|c|c|c|}
\hline \multirow{2}{*}{$\begin{array}{l}\text { Dosis } \\
\text { (gr/L) }\end{array}$} & \multirow{2}{*}{$\begin{array}{l}\text { Jumlah larva } \\
\text { (ekor) }\end{array}$} & \multicolumn{3}{|c|}{$\begin{array}{c}\text { Kematian pada } \\
\text { pengulangan (ekor) }\end{array}$} & \multirow[t]{2}{*}{ Rata-rata } & \multirow{2}{*}{$\begin{array}{c}\text { Rata-rata } \\
\text { (\%) }\end{array}$} & \multirow[t]{2}{*}{$\mathrm{pH}$} & \multirow{2}{*}{$\begin{array}{l}\text { Suhu } \\
\left({ }^{\circ} \mathrm{C}\right)\end{array}$} \\
\hline & & $\mathrm{Ke}-1$ & $\mathrm{Ke}-2$ & $\mathrm{Ke}-3$ & & & & \\
\hline 0 & 10 & 0 & 0 & 0 & 0 & 0 & 6 & 26 \\
\hline 10 & 10 & 0 & 0 & 1 & 0,3 & $3 \%$ & 6 & 26 \\
\hline 20 & 10 & 3 & 2 & 0 & 1,6 & $16 \%$ & 6 & 26 \\
\hline 30 & 10 & 2 & 4 & 4 & 2,6 & $26 \%$ & 6 & 26 \\
\hline 40 & 10 & 7 & 5 & 3 & 5 & $50 \%$ & 4 & 26 \\
\hline 50 & 10 & 8 & 9 & 7 & 8 & $80 \%$ & 4 & 26 \\
\hline
\end{tabular}


Tabel 6. LC $_{50}$ larvasida daun sirih

\begin{tabular}{cccc}
\hline Percent & Dosis & Lower & Upper \\
\hline 50 & 37,6918 & 34,0203 & 42,1737 \\
99 & 74,4065 & 64,7982 & 90,9853 \\
\hline
\end{tabular}

Hasil uji statistik dengan menggunakan kurva estimasi adalah sig< $\alpha$ $(0,000<0,05)$ bermakna secara statistik, artinya ada pengaruh larvasida bawang putih dalam membunuh larva Aedes spp.Nilai TU Larvasida bawang putih adalah 22,88. Hasil uji statistik dengan menggunakan kurva estimasi adalah $s i g<\alpha$ $(0,000<0,05)$ artinya ada pengaruh larvasida biji pepaya dalam membunuh larva Aedes spp. Nilai TU larvasida biji pepaya adalah 16,33. Hasil uji statistik dengan menggunakan kurva estimasi adalah $\operatorname{sig}<\alpha \quad(0,000<0,05)$ artinya ada pengaruh larvasida daun sirih dalam membunuh larva Aedes spp.Nilai TU larvasida daun sirih adalah 2,65.

\section{Larvasida Bawang Putih (Allium sativum)}

Suhu optimal bagi kehidupan dan perkembangan larva Aedes spp. berkisar antara $25-30^{\circ} \mathrm{C}$. Larva Aedes spp. membutuhkan $\mathrm{pH}$ optimal untuk hidup dan berkembang berkisar anatara $\mathrm{pH}$ 6,88,5[5]. Berdasarkan hasil uji toksiistas larvasida bawang putih, suhu $26^{\circ} \mathrm{C}$ dan $\mathrm{pH}$ 6. Artinya suhu dan $\mathrm{pH}$ tidak mempengaruhi kematian larva.

Potensi bawang putih menjadi larvasida di sebabkan kandungan yang ada pada bawang putih yaitu senyawa yang sudah ditemukan antaranya adalah Allicin dan Sulfur Amonia AcidAllin. Berdasarkan mekanisme tersebut maka Allicin dapat menghambat perkembangan larva yang akan berubah menjadi pupa dan akhirnya mati karena membran selnya telah dirusak. Kandungan minyak dalam larutan bawang putih juga mampu mengubah tegangan permukaan air sehingga larva mengalami kesulitan untuk mengambil udara dari permukaan air. Hal ini diduga menyebabkan larva tidak mendapat cukup oksigen untuk pertumbuhannya sehingga menyebabkan kematian larva [8].
Larvasida Biji pepaya (Carica papaya)

Suhu optimal bagi kehidupan dan perkembangan larva Aedes spp. berkisar antara $25-30^{\circ} \mathrm{C}$. Larva Aedes spp. membutuhkan $\mathrm{pH}$ optimal untuk hidup dan berkembang berkisar antara $\mathrm{pH}$ 6,88,5[5]. Berdasarkan hasil uji toksisitas larvasida biji pepaya, suhu $26^{\circ} \mathrm{C}$ dan $\mathrm{pH} 6$. Artinya suhu dan $\mathrm{pH}$ tidak mempengaruhi kematian larva.

Biji pepaya mengandung glucoside caricin dan karpain yang merupakan satu alkaloid yang terkandung dalam pepaya. Alkaloid karpain bersifat toksik dan menimbulkan reaksi kimia dalam proses metabolisme tubuh yang dapat menyebabkan terhambatnya hormon pertumbuhan, sehingga larva tidak dapat melakukan metamorphosis secara sempurna, bahkan mengakibatkan kematian[9].

\section{Larvasida Daun Sirih (piper betle)}

Suhu optimal bagi kehidupan dan perkembangan larva Aedes spp. berkisar antara $25-300^{\circ} \mathrm{C}$. Larva Aedes spp. membutuhkan $\mathrm{pH}$ optimal untuk hidup dan berkembang berkisar anatara $\mathrm{pH}$ 6,88,5[5]. Berdasarkan hasil penelitian uji tokisisitas larvasida daun sirih, rata-rata suhu $26^{\circ} \mathrm{C}$. Dalam penelitian ini suhu tidak mempengaruhi kematin larva. $\mathrm{pH}$ pada dosis antara 0-30 gr/L adalah 6, artinya pada dosis tersebut $\mathrm{pH}$ tidak mempengaruhi kematian larva. Sedangkan pada dosis $40 \mathrm{gr} / \mathrm{L}$ dan $50 \mathrm{gr} / \mathrm{L} \mathrm{pH}$ menjadi 4. pH yang berubah menjadi asam kemungkinan dapat mempengaruhi kematian larva.

Dalam daun sirih terkandung beberapa senyawa seperti minyak atsiri, zat penyamak, cineole, dan yang terpenting adalah senyawa alkoloid. Senyawa terakhir inilah yang nantinya dapat digunakan untuk membasmi jentik nyamuk dengan cara kerja mirip bubuk abate[6]. 
Selain itu, terdapat minyak atsiri yang apabila larva menghirup aroma dari minyak atsiri tersebut,akan menjadi racun pernapasan bagi larva nyamuk. Racun pernapasan tersebut akan menghalangi terjadinya respirasi tingkat seluler dalam tubuh serangga dan mengakibatkan enzim-enzim tertentu menjadi tidak aktif[9].

\section{KESIMPULAN DAN SARAN}

Bawang putih efektif dalam membunuh larva Aedes spp. LC 99 bawang putih 7,7 gr/L dengan batas bawah 6,7 gr/L dan batas atas 9,3 gr/L. Nilai Toxid Unit (TU) bawang putih adalah 26,88 . Biji pepaya efektif dalam membunuh larva Aedes spp. LC 99 biji pepaya adalah 10,22 gr/L dengan batas bawah 9,3 gr/L dan batas atas 14,22. Nilai Toxid Unit (TU) biji pepaya adalah 16,33.Daun sirih efektif dalam membunuh larva Aedes spp. LC99 daun sirih adalah 74,4 gr/L dengan batas bawah 64,8 gr/L dan batas atas 90,9 gr/L. Nilai Toxid Unit (TU) adalah 2,65.

Larvasida yang dapat diterapkan pada masyarakat adalah bawang putih. Karena nilai TU yang besar diantara ketiga jenis larvasida nabati. Penggunan larvasida bawang putih bisa dilakukan di tempat yang sulit dibersihkan.

\section{KEPUSTAKAAN}

1. Pinem, S. E. (2015). Efektiitas ekstrak daun jambu bii (Psidium guajava L.) sebagai larvasida nyamuk Aedes spp. pada ovitrap. Skripsi, Departemen Kesehatan Lingkungan FKM USU, http://download.portalgaruda.org.

Diakses pada tanggal 29 Desember 2016.

2. Sallata, M. H. (2014). Hubungan karakteristik lngkungan fisik dan kimia dengan keberadaan larva Aedes aegepty di wilayah endemis DBD. Skripsi, Universitas Hasanudin. Ujung Pandang. http://repository. unhas.ac.id. Diakses pada tanggal 7 Desember 2016.

3. Nugroho, A. D. (2011). Kematian Larva Aedes aegepty setelah pemberian abate dibandingkan de- ngan pemberian serbuk serai. Jurnal Kesehatan Masyarakat (JKM), 91-96. http://journal.unnes.ac.id/index.php /kemas. Diakses pada tanggal 11 Januari 2017.

4. Sulistyoningsih, Dwi dkk. (2009). Efektivitas larutan bawan putih dalam membunuh larva Aedes aegepty. Jurnal Kesehatan Volume 2 No 2 Desember 2009, Universitas Muhammadiyah Semarang.

http://Jurnal.unimus. Diakses pada tanggal 6 Januari 2017.

5. Utomo, M. (2010). Daya bunuh bahan nabati serbuk biji pepaya terhadap kematian larva Aedes aegypti. Laboratorium B2P2VRP Salatiga. Prosiding seminar nasional: Universitas Muhammadiyah Semarang. http://jurnal.unimis.ac.id. Diak-ses pada tanggal 29 Januari 2016.

6. Fahmi, M. (2006). Perbandingan efektivitas abate dengan ekstrak daun sirih. Artikel Ilmiah: Universitas Diponegoro Semarang. Jawa Tengah. http://eprints.undip.ac.id. Diakses pada tanggal 26 Desember 2016.

7. Sucipto, M. P. (2015). Influence of garlic (Allium sativum L.) extract as the larvacide of larva Aedes aegepty. J Majority Volume 4 No. 2: Universitas Lampung. Propinsi Lampung.http://juke.kedokteran.unil a.ac.id. Diakses pada tanggal 1 Januari 2017.

8. Hanani, S. J. (2014). Uji efektifitas larutan bawang putih sebagai insektisida nabati untuk membunuh larva nyamuk Aedes aegepty. Skripsi: Universitas Negeri Gorontalo. Gorontalo.http://kim.ung.ac.id. Diakses pada tanggal 1 Januari 2017

9. Wahyuni, D. (2016). Toksisitas ekstrak tanaman sebagai bahan dasar biopeptisida baru pembasmi larva nyamuk Aedes aegypti (Ekstrak daun sirih, ekstrak biji pepaya dan ekstak biji srikaya) berdasarkan hasil penelitian. Malang: Media Nusantara Creative. 
